\title{
"Are users the next entrepreneurs? A case study on the video game industry "
}

\author{
$\underline{\text { Auteurs }}$ \\ Thierry Burger-Helmchen, Claude Guittard
}

Document de Travail $n^{\circ} 2008$ - 14

Juin 2008

Faculté des sciences économiques et de gestion Pôle européen de gestion et d'économie (PEGE) 61 avenue de la Forêt Noire F-67085 Strasbourg Cedex

Secétariat du BETA Géraldine Manderscheidt Tél. : (33) 0390242069 Fax : (33) 0390242070 manderscheidt@cournot.ustrasbg.fr http://cournot2.u-strasbg.fr/beta

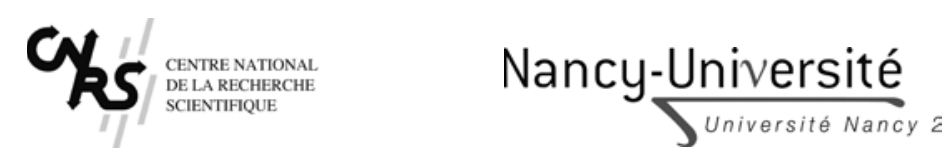

ulp 


\title{
ARE USERS THE NEXT ENTREPRENEURS? A CASE STUDY ON THE VIDEO GAME INDUSTRY
}

\author{
Thierry BURGER-HELMCHEN ${ }^{1}$ \\ Associate Professor \\ BETA - Bureau d'Économie Théorique et Appliquée \\ UMR 7522 - CNRS - ULP \\ 61 avenue de la Forêt Noire, 67085 Strasbourg Cedex, France. \\ Email : burger@cournot.u-strasbg.fr \\ Claude GUITTARD \\ Associate Professor \\ BETA - Bureau d'Économie Théorique et Appliquée \\ UMR 7522 - CNRS - ULP \\ 61 avenue de la Forêt Noire, 67085 Strasbourg Cedex, France. \\ Email : guittard@cournot.u-strasbg.fr
}

\begin{abstract}
Knowledge based-entrepreneurial firms struggle to survive because they must be simultaneously entrepreneurial on several dimensions. Can those firms rely on users to achieve sufficient efficiency in some entrepreneurial dimensions? To answer this question we drew on the entrepreneurial theories of the firm and on the users/innovator literature. In this work we present the plural entrepreneurship framework and then with a longitudinal case study of a mobile phone video-game firm which relies on users to improve their games we show that the user can significantly enhance the efficiency of the innovation of the firm. We also show that the other important dimensions of the firm behavior (organization, business model) can be significantly improved by the implication of users.
\end{abstract}

Keywords: Plural entrepreneurship; management of innovation; Video-game case study

\footnotetext{
${ }^{1}$ Corresponding author.
} 


\section{ARE USERS THE NEXT ENTREPRENEURS? : A CASE STUDY ON THE VIDEO GAME INDUSTRY}

Abstract: Knowledge based-entrepreneurial firms struggle to survive because they must be simultaneously entrepreneurial on several dimensions. Can those firms rely on users to achieve sufficient efficiency in some entrepreneurial dimensions? To answer this question we drew on the entrepreneurial theories of the firm and on the users/innovator literature. In this work we present the plural entrepreneurship framework and then with a longitudinal case study of a mobile phone video-game firm which relies on users to improve their games we show that the user can significantly enhance the efficiency of the innovation of the firm. We also show that the other important dimensions of the firm behavior (organization, business model) can be significantly improved by the implication of users.

Keywords: Plural entrepreneurship; management of innovation; Video-game case study 


\section{ARE USERS THE NEXT ENTREPRENEURS? : A CASE STUDY ON THE VIDEO GAME INDUSTRY}

\section{Introduction}

Many researchers believe that knowledge-based entrepreneurial firms struggle to survive because in these specific innovative activities they must be entrepreneurial simultaneously along several dimensions. Indeed, they must be entrepreneurial in the sense that they create a new product or a new service, but they must also be innovative in their business models and in the marketing strategies employed. Besides, they have to show some Schumpeterian entrepreneur skills to bind those elements together. Achieving simultaneously a good level of efficiency in all those entrepreneurial domains is difficult, therefore many start-up firms fail in their early years (Burger-Helmchen, 2008; Genus and Coles, 2006; Maurer and Ebers, 2006; Witt and Zellner, 2007).

In studying innovation we often insist on the accumulation of information and knowledge that is inherent to the process of innovation and product development itself (Merton, 1973; Romer, 1994; Hargadon and Sutton, 1997). Strong emphasis is put on the notions of sharing, accumulation and re-usage of information and knowledge in the knowledge management literature (Choo and Bontis, 2002). Therefore the process of devising new products and stimulating innovation by using the ideas of others is common in science and business. These "others" could be users who became involved in the process only by interacting with other users and firms. However we do not fully understand the conditions that shape an entrepreneurial firm's ability to build on the work of others (Katila and Ahuja, 2003). Previous studies have shown how innovative firms rely on social networks and communities to build on the ideas of others and the difficulties they encounter (Fleming, 2001).

Therefore the overarching question we address in this work is: Can entrepreneurial firms which must be entrepreneurial along several dimensions rely on users and user communities to achieve sufficient efficiency in some entrepreneurial dimensions? Addressing this question implies researching how innovation driven by users and the conditions surrounding the access and use of these innovative ideas can affect a firm's ability to innovate cumulatively and reach growth. 
The present paper is structured in the following manner. We use a longitudinal case study of a cell-phone video-game firm which relies on users to test and improve its games. This study shows the changing role of users in that specific sector of activity. On the basis of our case study, we show that users play an increasing role for these firms. Beside this beta testing role of users, this firm also relies heavily on users' hardware, namely their cell-phones. Today the development of a game for cell-phones needs to adapt the game to a wide range of cellphones; a game must be compatible with at least 300 models of phone the characteristics of which can differ widely. The firm cannot afford to buy 300 phones, so thanks to the variety of models owned by the users they it directly test the compatibility of its programs.

Then we link together the notions of plural entrepreneurship and the different types of users/innovators to obtain a longitudinal representation of the impact of the user on the boundaries and function of the firm. This contribution should enhance our ability to develop a more generalized approach in user innovation / plural entrepreneurship which should also be relevant for other industries than the video games for the phone industry.

We begin this paper with literature reviews. First a description of the notion of plural entrepreneurship and of the specific difficulties those kinds of firms encounter to survive and achieve growth. Then in a second point we briefly explore existing works on user innovation and pinpoint some differences existing in the user/innovator literature. These points are followed by a case history of a firm producing video games for cell-phones. We believe that this firm is a good example of plural entrepreneurship. This part of the work also presents the specificities of the relation between such kinds of small firms and the other actors of this industry. Those relations are bound to influence the cooperation between the user and the firm under study. We then present the evolution of the utilisation of the users as made by the firm under study we describe some managerial insight that we can draw from this case. A discussion and conclusion follow.

\section{Plural entrepreneurship and innovations}

Research on high-tech start-ups is a growing field of inquiry in the economic and managerial literature. The major recession for many start-ups at the beginning of this century confirmed the need to understand their difficulties to survive and the specificities of the knowledgebased entrepreneur behind those firms in comparison with regular entrepreneurs. The 
academic literature defines a high-tech start-up as a young firm (less than 8 years) launched by individuals for developing and exploiting (in various forms) an innovation (Shaw, 1990; Freeman, 1982). Regular entrepreneurship defines that innovation can be a product, a service, a process, a new commercial or organizational scheme. Knowledge-based entrepreneurship develops a somewhat different definition, which implies that the firm is a plural innovative bundle. Plural means that the firm must not only create a new product or new services, but also (if the product is really a novelty), find a new way of commercialising the product (a marketing/business model), and eventually develop an innovative organization of her activities.

The message that we try to deliver here is that the exploitation of new knowledge, sciencebased or not, implies the need to be entrepreneurial, not only for creating and exploring the knowledge, but also in bundling all the activities around the exploitation of the new knowledge. Arguments extending this view are given by Witt and Zellner (2007). For those authors a broad range of knowledge is needed to successfully accommodate the innovative patented technology and to commercially exploit it. Making the patented technology suitable for the market sphere, developing specific commercial and organizational practices is a core element of knowledge-based entrepreneurship. Witt and Zellner label those pluralentrepreneurial activities "entrepreneurial services" in opposition to the managerial services corresponding to the execution and supervision of existing ideas and operations. Alvarez and Barney (2007) and Metcalfe (2004) distinguish the plural-entrepreneurial activities in three main domains, the recognition and exploitation of technological (science-based) opportunities, of market opportunities and of institutional opportunities.

To achieve commercial success the new technologies must be placed into a representation of future markets (Boisot and MacMillan, 2004). Following this common representation building between the different entrepreneurs the resource gathering operations and coordination can start. Subsequently a third entrepreneurial dimension appears, corresponding to the integration of technological knowledge into the organization and commercial functions. This integration is not trivial and, with respect to the novelty in the product or service offered by the firm, a new organizational form must be put forward.

Some case studies already explored the concept of knowledge-based entrepreneurship. They represent the entrepreneurial activity as a whole, where a distinction is often made on the basis of a sole individual characteristic, a sole discipline or unit of analysis. Knowledge oriented entrepreneurship has been studied at different levels of analysis and in different 
contexts e.g. in the laser industry (Bünstorf, 2008) in biotech firms (Bureth et al., 2006; Zellner, 2003).

All these works underline that to be successful an entrepreneurial firm must have many links to existing firms or institutions and must be able to tie them together:

- links with science (public or private) in the case of biotechnology firms and the laser strings

- links with institutions, in the case of biotech for the agreement reason, for obtaining contracts and a sufficient level of demand for the products in the early time of the firm

- links with other firms in the industry, in the case of the development of standards

- links with users to fine tune the characteristics of the product

- links with users to develop the adequate business model

- links with users to diffuse the product.

In this work we are particularly interested in the last three points, how users can ease the creation of products and their diffusion, in the case of a small firm, with very limited resources. Based on the previous consideration we propose the following configuration of the plural-entrepreneurial dimension able to bring success (or not) in the start-up phase of a hightech firm (see figure 1).

\section{"INSERT FIGURE 1 ABOUT HERE"}

In this representation the success of a firm corresponds to the outcomes of pluralentrepreneurial activities. A science based/technology oriented entrepreneurial activity, an organizational/marketing oriented entrepreneurial activity and combinatory, Schumpeterian entrepreneurial activity to tie adequately all the pieces together.

The necessity to be entrepreneurial along several dimensions requires a procedural approach to describe the evolution of the entrepreneurial activities. Previous work on that topic developed our knowledge of the common traits on the genesis and growth of the firms, for instance they gave us a good understanding of the different phases of the development of firms (following a life cycle model) but by definition this separation in phases (or steps) focuses on the important points in each phase, neglecting somehow the relationships between the different elements and their co-evolution. The picture is then composed of the 
entrepreneur(s), the innovative products or services, the supporting activities, and the financial resources. The co-evolution of all these elements in relation with entrepreneurship fosters the survival of the firm. We add in the following the relation with users to achieve a better performance in the innovative activity.

\section{Users and innovations}

Many scholars have shown that users build on existing products or develop new products from scratch to serve their own needs. Of course not all the products developed by users become commercial products, and those few which reach commercialization have no guarantee that they will be successful. Nevertheless some user innovations have strongly influenced the rate and direction of the development pattern of some industries. In fact some industries are borne by users of close substitutes or people that create a completely new product to satisfy their needs. According to Baldwin et al. (2006) innovations made by firms can be labelled user innovation when one or more users of some goods recognize a new set of design possibilities and begin to explore it, jointly with the firm. As we will see, for the video game industry, the words “design” is a perfect one, because many video-game products include a level design phase and character design phase for which users are often involved.

This special issue on user innovation retraces many of the features of user innovation; let us just formulate some remarks and specificities for this study on video games. Many user innovation studies are devoted to industries which require a level of technical knowledge, and where the users innovate to ease their daily work (see von Hippel, 1988, for a reminder and analysis of scientific instruments, chemical processes or oil refining innovations). Other works on user/innovator are interested in users who develop products not for their work but for leisure and spare time activities. Therefore the users we study have more in common with those described by Shah (2005) on sports equipment.

We are not aware of any empirical study reflecting the process and amount of users becoming innovators in an industry like the video-game. But it seems that the users who innovate for leisure activities are relatively more numerous to enter entrepreneurial activities after their innovative effort than in other industries (Shah and Tripsas, 2007). Therefore for our case study we expected to encounter highly motivated users. Also this type of users is generally more likely to be actively involved in communities of users sharing information deliberately 
(Franke and Shah, 2002). Some studies show that the performances of these user innovation products are quite high. This can be explained by the fact that the users who are sufficiently skilled and determined to complete the innovation are often lead users, but they are not necessarily professionally involved in this field: they are more commonly hobbyists (Jeppesen and Frederiksen, 2006).

To sum up we can think of different types of user/firm relations, not all involving innovation at the individual level but all easing innovation development at the firm level (a similar list can be made with the notions of customers as resource, customers as cocreator and customers as user (Namnisan, 2002)) :

- The user innovator corresponds to the situation when the user innovates and hopes to ease his work or obtain some benefits from his innovation, or adapt an existing product to his needs (Shah, 2005). Therefore we are here close to the concept of lead user (von Hippel, 1986) referring to the ability of a minority of users to recognise a need long before the others (this is also similar to the definition of the perception by entrepreneurs given by Kirzner (1985) and the ability to develop an adequate solution to this need.

- Eventually this user becomes a user-manufacturer (Baldwin et al., 2006) to exploit his innovation commercially.

- The users bring also their help to customized, or fine tune products, by deleting errors in trial-and-error iteration necessary to achieve a good level of quality (Thomke and von Hippel, 2002).

- The user can also be a buzz creator easing the diffusion of the product (Hauser et al., 2006; Jeppesen and Frederiksen, 2006).

In the following we will try to match the plural entrepreneurial activities of the firm and these different forms of user/innovator/firm relations in our case study.

\section{The video game industry}

Over the last years the size of the video-game industry has experienced a strong growth, industry sales have more than tripled in the period 1996-2006 reaching today world market sales of approximately 30 billion dollars, with a third in the United States and growing 
importance of the European market (ESA). Some authors described the evolution of this industry by the use of innovation cycles (Burgelman et al., 2005). The industry experiences at this stage its sixth cycle. This cycle, like those before, is marked by a development of the calculation power available to programmers and the possibilities to create more and more graphically developed and realistic games for the users. What is new to this cycle, and began to appear with the previous one, is the development of a new mode of consuming games. The users do not play on dedicated machines, but on their phones.

Mobile games are one of the fastest growing segments of the game industry. However, mobile games are also some of the most challenging products to develop and distribute. Unlike most areas of the game business, mobile games must be created to run on hundreds of different phones, must pass quality assurance tests from dozens of organizations, and are marketed and sold unlike any other entertainment products (IGDA white paper). Also a recent development is the introduction on the phone game market of traditional game publishers. At an early stage mobile phone video games were principally produced by small firms, created to market some products. This was possible because the phone was not, technically speaking, very developed and only the idea mattered to produce a game on a low budget. Now that the phones have increasing computational power the budget to create a phone game increases. Also, big publishers in that industry diffuse modified versions of their computer and console games on phones as a marketing plan.

There are several actors in the video game industry, some specific to the phone game subindustry. The most important are developers, phone manufacturers, publishers, carriers and of course consumers. The consumers (users) are influenced by all the other actors of the industry, and all the actors rely on the users increasingly in the development of their products and services. In this work we focus on the relation between the users and the game developers. Nevertheless, the relation between our firm in the case study and the users is influenced by the other actors, let us briefly present them.

Game developer firms. The game developer firms in the mobile game business are the creators and producers of the initial game concept to the final saleable product. But their activity for mobile game developers is different from that for console or computer games. Mobile game developers must not only create and develop good games but they must make sure those games run on a wide variety of mobile phones. The obvious impact is that games must support whatever graphic format or audio format is available, screen sizes and processor 
power. Therefore a mobile game is generally produced in several versions with notable differences between them.

Game Publishers. The mobile publishing business is a mirror of the traditional video game business. The basic business model of the mobile game publisher is the same as in the PC and console video game industry. The game publishers acquire the rights to ideas or characters (movie based) of different products and typically fund the development of the game through internal or external studios to bring it to market. When they hire an external studio for developing a game (which is the case for the firm we studied) they usually give many specifications of what they expect to obtain as final products. Therefore the utilisation of users for such types of production is limited to testing and searching for bugs and errors and not so much for the development of innovative ideas.

Mobile phone manufacturers. The first mobile game console was created in 1997 by the firm Nokia who integrated the game Snake in one of its phones. The mobile phone manufacturers integrate in their products different run-time environments which include virtual machine or byte code environments such as Java. They often choose different run-time environments, coupled with proprietary features, which contributes to the fragmentation of the market and the difficulties to adapt a game to several phones. The mobile phone manufacturers play an important role in setting market directions of the technology that enables games and, in some markets can even play the role of distribution partner to publishers and studios in the form of pre-loaded demo versions of the game or by purchasing games that show off the latest and greatest technology. In this view, like the game publishers we mentioned previously, they give quality and content specifications that limit the employment of users to simple testing of the game.

Carriers. The wireless carriers are the equivalent of retail outlets in the traditional video game space. This group includes the large multinational carriers such as Vodafone, T-Mobile and Orange as well as the larger national carriers. Carriers wield significantly more power in the mobile gaming space than retailers do in the traditional game business because they have a monopoly over their very large customer base and game selection is usually not a criterion for most consumers in choosing their carriers. The carriers providing the network that connects the consumers to the publisher have therefore a monopoly power. Contrary to the two previous actors, the carrier does not check the content of the game, therefore he does not give specificities, the only criterion of importance is the size of the game, depending on which he will charge different prices for the carrying through the network. 


\section{Research methodology and presentation of the firm}

Because our main concern is to understand the links between users and plural entrepreneurship in the initial launching and growth phase of a small company, we collected and analyzed the data following a longitudinal case study methodology. Such an approach leaves plenty of room for interpretation, validation or reformulation of hypotheses by repeated interviews and confrontation of the answers given by the respondents. This allowed us to sketch somehow the motivations and rationality of the interviewed entrepreneurs and users (Macher and Richman, 2004).

The plural-entrepreneurial context we try to observe depends on the interaction of two types of elements, each of them can (and does) independently evolve during the life-cycle of the firm. The first type corresponds to the innovative elements. In a plural entrepreneurship context those elements correspond to innovation concerning product and service, the organization of the firm, the business model and marketing strategy. The second type corresponds to the evolution and eventually reaction of other firms and of the consumers at the industry level. These qualitative data are obtained by interviews with employees of the firm and with users and are completed by standard quantitative information (accounting data) and also quantitative data provided by the head of the firm such as the expected growth rate of the firm and the industry or of the employee turnover.

We had also access to a certain amount of information coming, among others, from reports, press releases and advertising articles for their products, which allowed us to determine the innovative nature of some games. Because these data can have different origins (internal or external to the firm), we checked their mutual coherence.

We first met the firm in 2005 and since then we have carried interviews with the employees and users for several projects on a regular basis, and a couple of students did their internships on the topic of organization and innovation in that firm, which provided us with a good idea of the evolution of the firm. Also, we participated ourselves in several "user testing days" including other users.

The firm was created in France in 2003 by three associates. In the following we describe the firm under the name F. Two of the associates came from the regular video game industry (PC games) and one from another multimedia; he was involved in web creation for associations. Their first game was an original in-house production, which won a prize at the International 
Mobile Gaming Award (IMGA). Although the firm won a prize, they encountered difficulties for marketing the game, but they were noticed by a major game publisher. The game publisher hired the firm for producing a game under a franchise he possessed. This was new for the firm who decided to produce games for the major publishers that are relatively standard in their concepts, and to produce in parallel its own original games. Therefore we could say that the firm finances its creativity and research by exploiting its competence to produce franchised games for the major game publishers.

Here we can notice that the creation of the firm corresponds to one type of users that we described previously, namely the user-manufacturer. The three associates at the origins of the firm created their own product and wished to commercialize it. Therefore they became entrepreneurs and founded their own small enterprise.

After the founding the firm has grown in size since the origins and amounts now to twelve persons. In 2005 the firm hired a person who had several tasks to fulfil, to organize the beta test with users, to market the original games they produced and to handle the relations with the game publishers. The organization of the beta test consisted of creating a group of users, who brought their own phones for doing the test. The test session in the first years of existence of the firm consisted then in downloading the game on their phones, and making them play, first in a free manner, then asking them to accomplish a certain sequence of moves. If the game did not crash or show problems, it was deemed acceptable for that specific phone. In case of bug reports the user was first asked to change some options of the game in a user friendly menu or to modify some elements of the phone (update the firmware), to see if it solved the problem. If the problem was not solved the organiser of the test session (we call him the integrator in the next) noted all the characteristics of the behaviour leading to the bug. He summarized then all the bugs and informed the programmer of what the different users had found. Not only did the users report the bugs and errors to the integrator but for some of them even provided a solution. Those users are usually students in the field of informatics who are willing to show their knowledge and learn some tricks of the business. The users we observe helping the firm and other users during the tests are also curious and willing to test the products some other users are developing.

Therefore we find here a second type of user implication. Their role was to perform some kind of beta test, mainly oriented to the detection of errors. This session was based on 
repetitive trials of different phones configuration. We found here an implication and employment of the users similar to that described by Thomke and von Hippel (2002) where the user detects the errors to ease the development process of the current product.

The users were also asked to express any suggestion for improvement or modification they found helpful to enhance the quality of the game but this was initially of minor importance for the firm. This aspect dramatically changed at the end of 2006. Around that time the firm began to use a program that generated virtually every phone existing on a PC. Consequently the utility of users having different types of phone to track program bugs disappeared. But the firm did not abandon her relation with users. They organized test sessions around the gameplay. Gameplay corresponds in video game terminology to the overall experience of playing the game including the immersion feeling, pleasure and addiction given by the game. The users were asked to list the elements of the game they liked and disliked, what they would like to see changed, and in which manner. Quite often the modifications were minor (change in colour, speed, difficulty), and those modifications were neither a new idea nor an innovation. But every now and then, the proposals were more complex, and could necessitate a major program adjustment. The integrator told us that the first time users made such big change proposals he was very confused. It was a test on a game for a major company; he knew that they could not introduce the modifications (although they would have enhanced substantially the fun of the game). They could not because of time pressure to finish the product and because of the specifications the game publisher enacted. Therefore he chose first not to report this to the programmer. Later after the test session, during an informal discussion with one of the entrepreneurs at the origin of the firm he told him the story. The entrepreneur asked him from then on to note all such proposals, if they could not be used for the current product, they could be interesting for future products. This became quickly of high importance for the firm and in 2007, the firm hired one more person to organise the test sessions and help the previous integrator in his tasks.

This corresponds to a third type of user / firm relation with this time a more important role on the product innovation side. What the users try to do is to influence the development of the product and shape the product in conformity with their taste but also what they expect to be the future taste of other players. These modifications demanded huge modification of the interface and corresponding programming time. Also, when the game tested was not an original game of the firm, but one they had to make to order for a major game publisher significant modifications from the original project were not possible. Therefore it was not 
possible to implement these ideas in the current product, but the team managers were careful to implement them in the next game they developed, either in an original game, or as a sequel of a game in the project development phase before a major game publisher approved it.

That innovations and improvements occur during the development phase are nothing new in the video game industry. Cohendet and Simon (2007) report two types of creativity in the development process of a video game, the micro and the macro-creativity. The microcreativity corresponds to what emerges during the daily activity of the programmers, macrocreativity corresponds to what is created and decided once and for all at the beginning of the project by the team manager. In our example, the important, innovative ideas of the users are incorporated during the macro creative phase. Also we could make a distinction between the creative improvement coming from the firm and those coming from the users outside the firm. We circumscribe the firm creativity at the beginning of the project as macro creativity, and, because the creativity coming from the users is developed after the programmers did their work (micro) and it is integrated not in the current game, but in the next generation of products (macro), we label it meso-creativity.

As stated by the firm, it was not necessary to invest many resources in communication and community development. The community development was to a large extent managed by only one (later two) person. The task was relatively easy for several reasons. First the firm is located in a city with a very large university, therefore there are many students who are willing to do this kind of job, and they are easy to hire for a minimal price. For some of them, they received only the reimbursement of the travel costs (inner city metro) and a collection of previous games made by the firm for their phones. Later when the firm began to grow, small amounts of money where also distributed. Also, the members of the firm are all very young, and not so different in their language and habits from some older students. This eases communication between the users and firm members. One could think that speaking of video game, the students that would be attracted would be mostly students in computer science or eventually active in multimedia creation. But the origins of the users in terms of studied fields are very heterogeneous. However it is true that those few who contributed to the development of new ideas and innovation were for the most part involved in computer science or similar studies. Also speaking about video games and computers one could expect to see people involved in the hacking community. In the case of our study we encountered no user involved in such activities (or saying so). 
Finally, even this recruitment modality of the users was modified, the firm tries now to hire user testers by direct contact in phone stores or video game stores (we already mentioned the importance of mobile phone manufacturers and carriers). In searching the game testers in that way, the firm tries to create a buzz, to find some prime users who will diffuse information concerning the game. This is also a way of relying on users to develop one dimension of the firm, the marketing dimension.

We asked the firm about all the products that were tested by users. None has been born yet by the sole user involvement, but many products have incorporated ideas proposed by the users including an idea for a logic game (Tetris like) which has been transformed by the firm into a game and several sequels. So far, we can say that the users help the firm to develop new products, and hence to be more entrepreneurial. Also, the ideas generated at a low cost allow the firm to concentrate more resources on the development of the business model and marketing relations with the big game companies and carriers. In an indirect way the users help also the firm to achieve greater efficiency on that dimension of her activity.

In the following we link more precisely the notion of plural entrepreneurship and user types we described.

\section{Users, innovations and plural entrepreneurship: some managerial insights}

We now tie together the different types of users we observed in the case study with some dimension of the plural entrepreneurship approach of this start-up firm. To facilitate the discussion we plot the elements related to the plural representation and to the different types of user involvement on a figure. On Figure 2 the vertical axis distinguishes different dimensions involved. With respect to our case study we retain three dimensions (i) the organization development, (ii) the different project development, and (iii) the development of the business model and marketing approach. The horizontal axes correspond to the development of each dimension through time. On this representation, each time a different type of user is involved we mark it with a circled user sign.

"INSERT FIGURE 2 ABOUT HERE" 
We start our discussion on the upper left part of Figure 2 with the organization development of the firm. Two major phases can be identified: the launching of the firm and the development of the firm. The launching of the firm corresponds to the moment where users became founders of the firm to exploit a product they designed for their own pleasure and they expect to please other players (mark user1). We found here the traditional lead user who becomes a manufacturer and entrepreneur to commercialise the product he created (Baldwin et al., 2006). The second phase of the organization development corresponds to the situation where the firm engages in the development of several projects simultaneously.

The next dimension on the figure corresponds to the project development, where product innovation occurs. The users help the firm in two ways along this dimension. First by seeking errors in the program, possible bugs that appear depending on the phone device employed. This corresponds to the user2 mark on the figure. Secondly, by proposing substantial modifications and creative ideas than can result in an innovative new product for the firm. This activity refers to what we called meso-creativity, when the ideas of the users are implemented in the next generations of products. This corresponds to the user3 mark on the figure. When the firm began to develop several games simultaneously, the user2 and user3 became of utmost importance for the firm and are certainly a source of explanation for her survival and growth.

The final dimension we observed was the business model and marketing approach of the firm. This approach changed from a first phase where the firm made a standalone attempt at selling the product through internet on her own website, then rapidly on the website of game aggregators with no more success. Then, in a second phase, the firm rapidly transferred this task to the game publishers. This move allowed the firm to concentrate on the development of products. But recently a new approach of the commercial activity was initiated by trying to identify important consumers in phone shops, game shops, and to hire them for game tests, or to distribute early versions of the game hoping for diffusion through word of mouth thus creating a sort of buzz. This is labelled user4 on the figure.

Figure 2 and the description we made explain quite well why the involvement of users works well for the firm. The user/innovator literature explains why the firm exists, because some users became entrepreneurs. And it explains also why the firm encounters successful growth (fine tuning of products and creation of new products with users). But why does it also work for the users? What are their interests in doing that? We can give some arguments on that point that entail some managerial implications. Some motivations are close to those 
encountered in the open source software literature: Financial interest (Lerner and Tirole, 2002) and technological interest (Weber, 2004). Some other incentives need to be discussed:

- Learning (Lakhani and von Hippel, 2003): this motivation is much less developed than in the case of OSS due to the simple fact that the cognitive implication is far less demanding.

- Altruism (Zeitlyn, 2003): of course we can observe this motivation because at first it was only a hobby without pay. In fact, this motivation is called by the "beta testers" to "have fun”.

- Community membership (Bonaccorsi and Rossi, 2003): we could imagine that the fact that the interactions occur in small groups face to face, could diminish the feeling of community membership. On the contrary, people have the strong feeling to be a member of the "firm F." community. We have observed phenomena characteristic of community feeling and altruism, such as important exchange of information, experiences, or personally developed basic video games.

- Career incentive (Lerner and Tirole, 2002): even if in our case we have not observed any hiring by the firm F. of a member of the users' community. This plays an important role for the users, at least, as a positive signalling in their resumes, since most of them would like to work in the video game industry.

- Peer reputation (Lerner and Tirole, 2002): once again the task of the users is much less demanding, so the peer reputation incentive is not direct. But we observe a strong incentive based on social reputation. Indeed thanks to this activity of "beta testing” they can play with games which are not yet on the market.

From the point of view of managers, they have to take into account the particular characteristics of motivations and trust with users who are deeply involved in the process of innovation but are not members of this organization.

By studying the firm and their relations with the users we identified several conditions necessary for this relation to lead to an innovation for the firm. The general managerial practices and organization of the firm played an important role in the management of the access among different generators of innovation. It remains a strategic decision of the firm to diffuse the collected information to all the members of the firm, as is the much more critical decision to diffuse the internally developed innovation (here the program codes) to the outside 
(some selected and highly skilled users). Such strategies have been often reported by scholars studying big firms, frequently in relation with patenting or disclosure dilemmas, for companies such as Microsoft, Cisco, Intel or Sun Microsystems (Gawer and Cusumano, 2002; Garud et al. 2002). If it is strategically important for big firms, it does not mean that it is of lesser importance for small firms. Of course the scale is different, and the number of users able to build on the platform shared by the companies mentioned is not comparable with the handful of users allowed to have the codes and development platform in our case study. But the impact for the firm can be very positive, guiding her to some new ideas. Not to mention that it can lead to a better choice for future recruitment of collaborators if one of those proves to be brilliant.

The involvement of users to produce innovation is more and more commonly employed by firms in the entertainment business (Jeppesen and Frederiksen, 2006). This case study is an opportunity to look at the strategies and organization forms video game manufacturers should adopt to create dynamic capabilities based on the users/ firm interaction. Small entrepreneurial firms and not only big firms should be interested to know that they can build a comparative advantage in involving users at an early stage of video game design and not only in the beta test part that occurs at a time when the product should be urgently commercialised and when no big modification can or should be introduced by the firm. Expressed in the language of resource-based view (Barney, 1991), users can be a strategic asset because they are imperfectly imitable, difficult to acquire and rare (strictly speaking of users turned innovators). Also if those firms wish to grow they must understand how the other firms in the industry (especially the big firms and diffusers) influence users by their products or declarations, or interact with users to eventually find a niche corresponding to a special game design or concept.

\section{Conclusion}

This work began by addressing the question whether firms who must be entrepreneurial along several dimensions (plural entrepreneurship) can rely on users to achieve sufficient efficiency in some entrepreneurial dimensions. To answer, we drew on the entrepreneurial theories of the firm and users/innovator literatures. This study allowed us to show that some difficulties encountered by small firms, in particular those in innovative industries and necessitating 
plural entrepreneurship can be overcome by sharing information and knowledge with some chosen users.

This discussion raises clear opportunities for further research on plural entrepreneurship and user innovation. We see two main directions of work involving each time notions of entrepreneur, manager and integration of knowledge.

In the first place in this work we make a very direct assumption on the integration of knowledge and information by the firm. In our case study we give this role to the integrator of the firm, but what happens with such an individual in different forms of organization? The study here was limited to plural entrepreneurship with users involved in entrepreneurship on only one dimension. Could it be possible that the users are involved in other dimensions? What happens with the user / firm relation when the firm builds on diffused entrepreneurship or network entrepreneurship?

In the second place, once we know that the situation can be different from one organizational form to another we can ask who decides which knowledge / information is to be shared and who governs the relation with the users? We can assume that managers play a key role to insure the interface between the firm and the users community. Indeed, if ideas and knowledge are held by user-entrepreneurs, who wish to put their ideas into action, the role of the manager is then to organize that specific knowledge. Similar questions have been addressed about the division of labour and division of knowledge by several authors (Becker et al., 2007). Does their framework separating knowledge and labour, managerial power, and creative entrepreneurship help understand the relation between the users and the firm for obtaining innovation?

\section{References}

Alvarez, SA and JB Barney (2007). Discovery and creation: alternative theories of entrepreneurial action. Strategic Entrepreneurship Journal, 1, 11-26.

Baldwin, C, C Hienerth and E von Hippel (2006). How user innovations become commercial products: A theoretical investigation and case study. Research Policy, 35, 9, 1291-1313.

Barney, J (1991). Firm resources and sustained competitive advantage. Journal of Management, 17, 1, 99-121. 
Becker, MC, P Cohendet and P Llerena (2007). Division of labor and division of knowledge: Why the nature of causality matters for the evolutionary theory of the firm. In Cantner, $U$ and F Malerba (ed.): Innovation, Industrial Dynamics and Structural Transforation: Schumpeterian Legacies, Springer, 49-66.

Boisot, M and IC MacMillan (2004). Crossing epistemological boundaries: managerial and entrepreneurial approaches to knowledge management. Long Range Planning, 37, 505-524.

Bonaccorsi, A and C Rossi (2003). Why open source software can succeed. Research Policy, 7, 32, 1243-1258.

Bünstorf, G (2008). Knowledge-based entrepreneurship and technology transfer: Evidence from the German laser industry. In Malerba, F. (ed.): Knowledge-Based Entrepreneurship: Evidence from Europe. Cambridge UK: Cambridge University Press, forthcoming.

Bureth, A, J Pénin and S Wolff (2006). Entrepreneurship in biotechnology : The case of four start-ups in the Upper-Rhine Biovalley. BETA Working Paper 2006-21, University Louis Pasteur, Strasbourg.

Burgelman, R, A Grove and P Meza (2005). Strategic dynamics: Concepts and cases. New York: McGrawHill/Irwin.

Burger-Helmchen, T. (2008). Plural-entrepreneurial activity for a single start-up: a case study., Working paper BETA 2008-01, forthcoming in Journal of High Technology Management Research.

Choo, CW and N Bontis (2002). The strategic management of intellectual capital and organizational knowledge. Oxford University Press.

Cohendet, P and S Laurent (2007). Playing across the playground: paradoxes of knowledge creation in the videogame firm. Journal of Organizational Behavior, 28, 5, 587-605.

ESA, Entertainment Software Association, http://www.theesa.com.

Fleming, L (2001). Recombinant uncertainty in technological search. Management Science, 47, 1, 117-132.

Franke, N and S Shah (2003). How communities support innovative activities: an exploration of assistance and sharing among end-users. Research Policy, 32, 1, 157-178.

Freeman, C (1982). The economics of industrial innovation, Frances Pinter.

Garud,R, S Jain and A Kumaraswamy (2002). Institutional entrepreneurship in the sponsorship of common technological standards: The case of Sun Microsystems and Java. Academy of Management Journal, 45, 196-214.

Gawer, A and MA Cusumano (2002). Platform leadership: How Intel, Microsoft, Cisco drive industry innovation. Harvard Business School Press.

Genus, A and AM Coles (2006). Firm strategies for risk management in innovation. International Journal of Innovation Management, 10, 2, 113-126. 
Hargadon, A and RI Sutton (1997). Technology brokering and innovation in a product development firm. Administrative Science Quarterly, 42, 716-749.

Hauser, J, Tellis, G and J Griffin (2006). Research on Innovation: A Review and Agenda for Marketing Science. Marketing Science, 25, 6, 687-717.

IGDA, International Game Developer Association, http://www.igda.org

Katila, R and Ahuja (2002). Something old, something new: A longitudinal study of search behavior and new product introduction. Academy of Management Journal, 45, 1183-??.

Kirzner, I (1985). Perception, Opportunity and Profit Studies in the Theory of Entrepreneurship, University of Chicago Press.

Jeppesen, LB and L Frederiksen (2006). Why do user contribute to firm-hosted user communities? The case of computer controlled music instruments. Organization Science, 17: 45-63.

Lakhani, K and E von Hippel (2003). How open source software works: "Free” user-to-user assistance. Research Policy, 32, 923-943.

Lerner, J and J Tirole (2002). Some simple economics of the open source. The Journal of Industrial Economics, 50, 2, 197-234.

Maurer, I and M Ebers (2006). Dynamics of social capital and their performance implications: Lessons from Biotechnology start-ups. Administrative Science Quarterly, 51, 262-292.

Macher, JT and BD Richman (2004). Organisational responses to discontinuous innovation: a case study approach. International Journal of Innovation Management, 8, 1, 87-114.

Merton, R (1973). The sociology of science: Theoretical and empirical investigations. University of Chicago Press.

Metcalfe, JS (2004). The entrepreneur and the style of modern economics. Journal of Evolutionary Economics, 14, 157-176.

Nambisan, S (2002). Designing virtual customer environments for new product development: Toward a theory. Academy of Management Review, 27, 3, 392-413.

Romer, PM (1990). Endogenous technological chance. Journal of Political Economy, 98, 5, 71-102.

Shah, S (2005). From Innovation to Firm Formation in the Windsurfing, Skateboarding, and Snowboarding Industries. University of Illinois Working Paper \#05-0107.

Shah, S and M Tripsas (2007). The accidental entrepreneur: the emergent \& collective process of user entrepreneurship. Strategic Entrepreneurship Journal, 1, 1, 123-140.

Shan, W (1990). An empirical analysis of organizational strategies by entrepreneurial hightechnology firms. Strategic Management Journal, 11, 2, 129-139. 
Thomke, S and E von Hippel (2002). Customers as Innovators: A New Way to Create Value. Harvard Business Review, 80, 4, 74-81.

von Hippel, E (1986). Lead users: A source of novel product concepts. Management Science, 32, 7, 791-805.

von Hippel, E (1988). The sources of innovation. Oxford: Oxford University Press.

von Hippel, E (2005), Democratizing innovation, MIT press.

Weber, S (2004). The Success of Open Source. Harvard University Press, Cambridge.

Witt, U and C Zellner (2007). Knowledge-based entrepreneurship: The organizational side of technology commercialization. In Malerba, F and S Brusoni (eds), Perspectives on Innovation (pp.352-371), Cambridge University Press.

Zeitlyn, D (2003). Gift economies in the development of open source software: anthropological reflections. Research Policy, 7, 1287-1291.

Zellner, C (2003). The Economic Effects of Basic Research: Evidence for Embodied Knowledge Transfer via Scientists' Migration. Research Policy, 32, 1881-1895. 
Figure 1. Plural-entrepreneurship and outcomes at the firm level

Dimension of entrepreneurship Outcome good (bad)

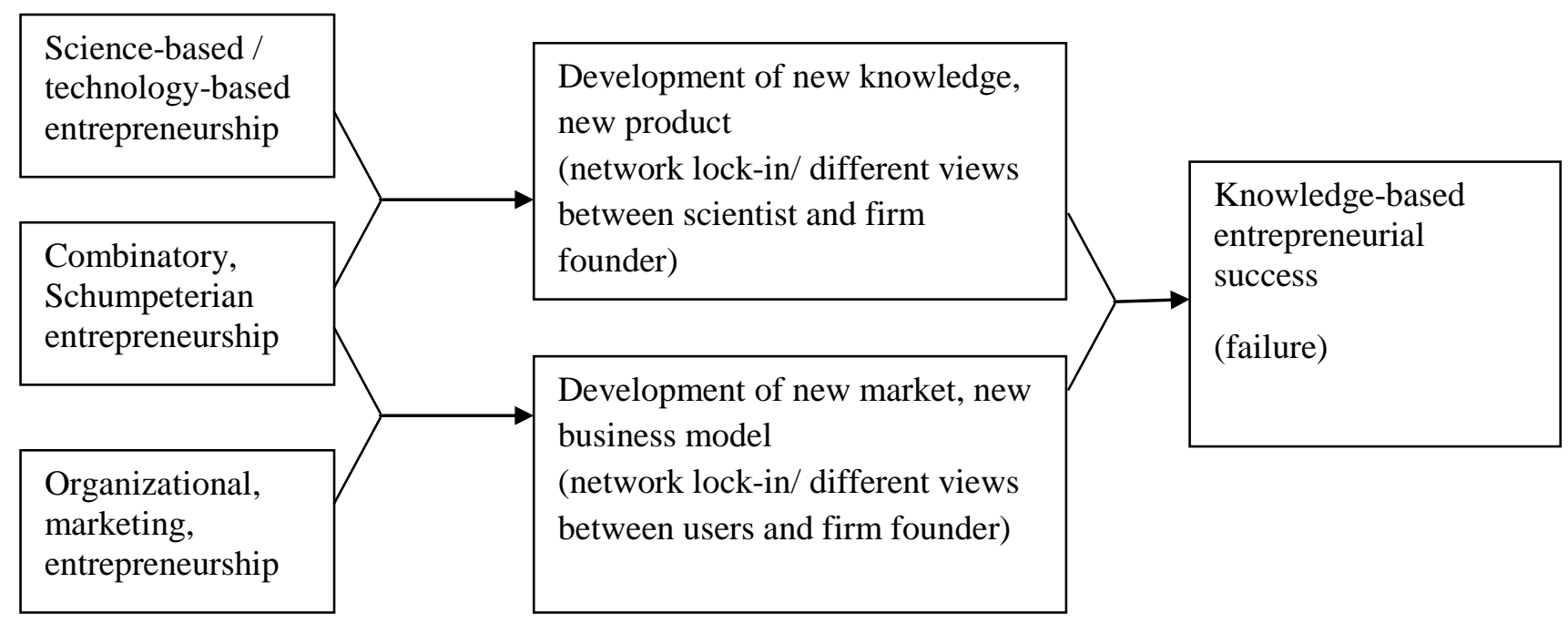


Figure 2. How users ease plural-entrepreneurship at the project and firm level

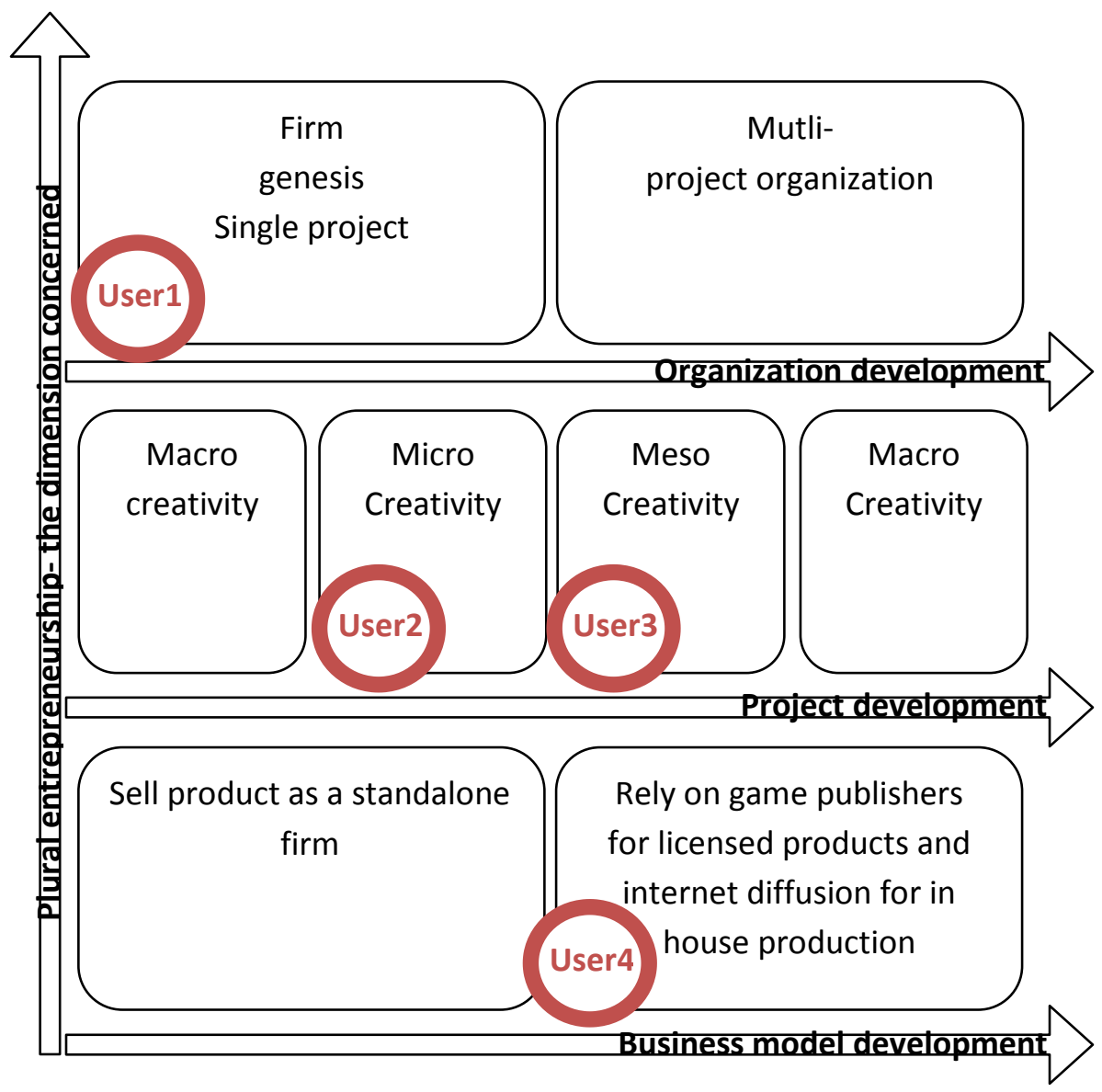

